\title{
THE FLORIDA FLYTRAP MYSTERY IS SOLVED
}

JIM MILLER • Tallahassee • Florida 32308•USA • jim_miller@mindspring.com

For many years, there has been much speculation as to how colonies of Dionaea muscipula — the Venus' Flytrap — appeared in the Florida Panhandle in Liberty County. Theories ranged from seed stuck to the feet of migrating birds to a former seller of "three bulbs for a dollar" flytraps planting them as a backup in case populations ran low in the Carolinas. Some even suggested they had been here all along, just undiscovered until more people began venturing into bogs and savannas in search of carnivorous plants.

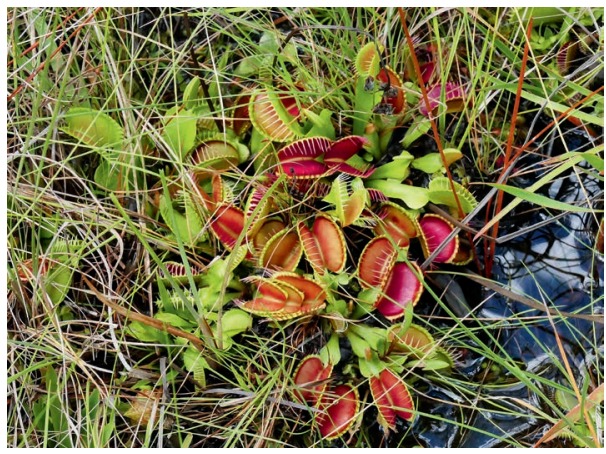

At last we have the answer, and it is none of the above.

Considering the fact that I have been exploring locations throughout the southeast regularly since 1971, and how many people I have gotten to know over those nearly 50 years, I am actually shocked that it took this long to make the right connections and discover the person responsible for flytraps appearing in several areas in and around the Apalachicola Forest.

Not long ago I received an email from a person whom I will not name, as I do not have his permission to do so. In part, the message read:

"You do not know me, but I am a CP grower as well. I read your Pinguicula article in CPN this month, and saw that you are from Tallahassee. I was born and grew up there for about 30 years and know the area quite well. My mother worked for the U.S. Forest Service... and we often explored the Apalachicola National Forest where I discovered acres and acres of Sarracenia. As a kid, I was taken by these plants and now I am 79 years old and still love them. I am not a seller, but just collect them because I love them. I now have a rather extensive collection of around 6000 plants (mostly two- and three-year-old seedlings) of Sarracenia that I have bred. I have about 40 registered cultivars.

"...I retired in 2001. Since then I renewed my interest in carnivorous plants and now have 18 large outdoor beds where I grow Sarracenia.

"In 1973 or 1974, I had collected quite a few Venus Flytrap seeds and returned to Tallahassee to visit my mother. I drove out (to areas) near Hosford and threw out my seeds in three different locations. Then forgot all about them. About 30 years later, I heard there were some flytrap colonies in that area and people were wondering how they got there. I don't know if mine survived, but I suspect some did. I met a grower friend here in NC who had gotten some flytraps from a friend in California, who had gotten them from 'the Hosford Bog.' He gave me some of those... plants, so now, maybe I have some of my plants from that original planting (decades) ago.”

This account was confirmed for me by a person who lives in Tallahassee and knew of the seed being scattered in the early 1970s. A few other longtime Tallahassee residents may also well know this person from the short-lived Florida Carnivorous Plant Society. I was surprised I had never heard his name in all the years I have lived here, but we have exchanged emails several times. Mainly it's nice to finally have an answer as to the origin of the flytraps that grow about an hour from my doorstep! 